\title{
Size does not matter: commensal microorganisms forge tumor- promoting inflammation and anti-tumor immunity
}

\author{
Melanie R. Rutkowski ${ }^{1}$, Jose R. Conejo-Garcia ${ }^{1}$ \\ ${ }^{1}$ Tumor Microenvironment and Metastasis Program, The Wistar Institute, Philadelphia, USA
}

Correspondence to: Jose R Conejo-Garcia, email: jrconejo@Wistar.org

Keywords: microbiota, inflammation, cancer, TLR5, gamma delta T cell

Received: February 23, $2015 \quad$ Accepted: March 16, $2015 \quad$ Published: March 23, 2015

This is an open-access article distributed under the terms of the Creative Commons Attribution License, which permits unrestricted use, distribution, and reproduction in any medium, provided the original author and source are credited.

\section{ABSTRACT}

Recent studies have demonstrated that the commensal microbiota are indispensable for the maintenance of immune homeostasis, orchestration of immune responses against pathogens and most recently during cancer immunotherapy and malignant progression of extraintestinal tumors. Here we discuss the recent findings that a common genetic variation in TLR5 influences the progression and outcome of ovarian, sarcoma, and luminal breast tumors and the implications of these findings in light of recent publications describing the role of the commensal microbiota in control of the systemic immune system.

\section{COMMENSAL MICROORGANISMS ARE REQUIRED TO FORGE A ROBUST IMMUNE SYSTEM}

Barrier surfaces in humans are colonized with trillions of microorganisms including hundreds of different bacterial and fungal species, as well as viruses and protozoans $[1,2]$. These commensal microorganisms colonize the upper respiratory tract, genitourinary tract, skin, and intestines shortly after birth. Only in the intestine, it is estimated that the number of bacteria is around $10^{14}$, outnumbering eukaryotic cells at a ratio of 10:1 [3].

Recent studies have demonstrated that commensal microorganisms are required to maintain the metabolic needs of the host, but also for the immune homeostasis of mucosal surfaces $[4,5]$. As importantly, the microbiota also plays a crucial role in the postnatal development of the immune system [6]. Commensal microorganisms contribute to forge the development of a robust immune system that is able to defend the host from infections and tumors at places that are distal from colonized locations [7]. Although our understanding of these mechanisms is in its infancy, the relevance of the microbiota during immune development is evidenced by significant decreases in both conventional CD4 T cells [8] and regulatory T cells [9] in the spleens of germ-free mice, compared to their normally colonized counterparts. In the absence of commensal microorganisms, mice also develop a narrower repertoire of TCR clones [10], and their T cell compartment is severely defective and skewed towards a Th2 response [11]. Correspondingly, microbial colonization of germfree animals drives an increase in immunoglobulin levels and enhances systemic immune responses [6].

Given the importance of the microbiome in postnatal immune development, the presence $\boldsymbol{v}$ s. the absence and/ or the composition of the microbiota have been found to play a role in different diseases associated with adaptive immune responses. Microbiota-induced IL-1 $\beta$ production, for instance, has been also shown to be required for Th17 differentiation in the intestine [12]. Correspondingly, the course of various models of autoimmunity that rely on IL-17-driven inflammatory responses - including diabetes [13], collagen-induced arthritis [14], or experimental colitis [15] - is significantly influenced by commensal bacteria.

Commensal-derived signals are also required for optimal immune defense against systemic pathogens. Nod1-mediated recognition of commensal-derived peptidoglycan primes neutrophils to rapidly respond to pathogenic bacterial infection [16], whereas during viral infection, the commensal microbiota are required to maintain a basal level of type I IFN signaling that determines the activation threshold of innate immune responses [17]. Correspondingly, a previously unappreciated role in driving protective antibody responses in response to influenza vaccines has also been 
recently identified for commensal bacteria, whereby, vaccination responses were significantly impaired in germ-free or antibiotic-treated mice and restored by reconstituting the microbiota with flagellated bacteria [18].

\section{COMMENSAL BACTERIA INFLUENCE SPONTANEOUS TUMOR PROGRESSION AND THERAPEUTIC RESPONSES}

A role for the microbiota has also been associated with carcinogenesis through both metabolic alterations and the promotion of inflammatory responses [3]. More importantly, because solid tumors are invariably associated with inflammation, it is not surprising that certain commensal bacterium promote carcinogenesis locally in the colon, where they are more abundant [19]. This is consistent with the role of chronic inflammation in the intestinal tract (e.g., ulcerative colitis) in the promotion of colon cancer, an association known for years. However, until very recently, the role of the commensal microbiota in influencing the progression of systemic extraintestinal cancers has remained unknown. These studies have either focused on the role of immunological defects that result in significant dysbiosis and bacterial translocation to the liver, or have focused on the role of commensal microbiota in the presence of an unharmed mucosal barrier. For instance, emerging evidence suggests that a subset of intestinal NKp46(+) lymphoid tissue-inducer (LTi) cells could play a role in the suppression of (distal) B16 melanoma [20]. Even more recently, Goldszmid, Trinchieri and Zitvogel simultaneously reported for the first time how interactions between microbiota and mucosal surfaces are required for therapeutic responses to different anticancer interventions against tumors occurring outside of the intestinal tract [21-24]. In these seminal reports, it was conclusively demonstrated that chemotherapeutic agents such as oxiplatinum and immunomodulatory agents such as CpGs both require commensal bacteria for inducing tumor rejection, because depletion of commensal bacteria with antibiotics resulted in consistently accelerated malignant progression. However, differential effectiveness is driven by dissimilar mechanisms: myeloid cell-derived TNF- $\alpha$, produced in response to TLR activation, likely with the contribution of type I IFN, are needed for the curative effects of CpGs combined with anti-IL-10R antibodies, and are dependent on the presence of gut commensal bacteria [23]. In contrast, the optimal anticancer effects of chemotherapeutics such as cyclophosphamide require anti-commensal Th17 and memory Th1 responses, which are facilitated by enhanced intestinal permeability and subsequent bacterial translocation caused by these drugs $[22,23]$.

The obvious implication of these studies is that antibiotics can compromise the efficacy of certain anticancer treatments. However, in the absence of treatment, we have demonstrated that the progression of tumor models of sarcoma, cervical cancer and ovarian carcinoma is significantly delayed when intestinal bacteria are depleted with a cocktail of broad-spectrum antibiotics [25]. Our study shows that the microbiota, in a TLR5 signaling-dependent manner, drives the up-regulation of tumor-promoting IL- 6 in the serum of tumor-bearing mice, subsequently promoting MDSC mobilization [25, 26]. Expanded MDSCs in turn influence $\gamma \delta$ T cells to secrete immunosuppressive galectin-1, which abrogates antitumor immunity and accelerates malignant progression.

In contrast, there is a second class of tumors characterized by relatively low production of IL-6 and exemplified by luminal (but likely not basal) breast cancer. In these tumor systems, depletion of commensal bacteria in wild-type mice accelerates extra-mucosal tumor growth [25]. Interestingly, blockade of tumor-promoting IL-17 in the absence of high levels of IL- 6 significantly delays malignant progression, while the same intervention has no effect when serum IL-6 levels are higher [25].

Overall, our results underscore the critical role of commensal bacteria in tumor progression, by governing the orchestration of tumor-promoting inflammation. Inflammatory responses depend on both hematopoietic cells and the capacity of tumor cells to secrete IL-6 in an autocrine and paracrine manner. Correspondingly, preventing the capacity of tumor cells to up-regulate IL-6 through different shRNA clones is sufficient to: 1) significantly decrease serum IL-6 levels; 2) diminish MDSC mobilization; 3) reverse the galectin-1-dependent regulatory activity of $\gamma \delta$ T cells; and 4) render previously IL-17 insensitive tumors susceptible to IL-17 blockade. Most importantly, although bigger cohorts of patients and independent datasets are needed to indisputably confirm the relevance of these findings, our data suggest that (IL$6^{\text {hih }}$ ) ovarian and (IL-6 $\left.{ }^{\text {low }}\right)$ luminal breast cancer patients recapitulate the mechanisms identified in our mouse models [25].

\section{SPECIFIC DEFFECTS IN INNATE IMMUNITY PROMOTE BACTERIAL TRANSLOCATION AND DYSBIOSIS}

An important consideration to understand the role of the microbiota in health and disease is how differences in the composition of the commensal microflora could influence experimental differences across different laboratories. The occurrence of colitis in the absence of certain immunological sensors in some facilities, for instance, has been also reported as a major contributor to accelerated malignant progression. However, the mechanisms driving accelerated tumor growth under these conditions are very different from the ones that we observed in tumor-bearing hosts with a preserved mucosal barrier. For instance, defects in various components of 
the inflammasome, including Nlrp6, Nlrp3 and Capase-1 cause dysbiosis and intestinal inflammation in some facilities [27-29]. This results in microbial products leaking through the portal vein to the liver, where they activate inflammation and promote fatty liver disease, with dramatic metabolic changes in the host.

Some important factors that impact microbiomedependent mechanisms in multiple ways include the hygiene of the facility; the nature of the diet; and the $\mathrm{pH}$ of drinking water. The incidence and progression of diabetes in NOD mice, for instance, are profoundly influenced by the administration of acidic vs. neutral water [30, 31]. Mice receiving acidic water mice also experienced significant changes in their bacterial repertoire, including an increase in the abundance of Bacteroides. This may contribute to explain experimental differences in the occurrence of a metabolic syndrome across different vivariums, because certain laboratories (e.g., the Jackson Laboratory) provide their mice with acidified drinking water, safeguarding the cleanliness of the water and reproducibility across experiments with the consequence of altering the microbiome. In contrast, mice receiving neutral water could have alterations to their microbiota, depending on the hygiene of the facility and contaminants in their drinking bottles. For instance, we [25] and others [32] have not observed any evidence of intestinal inflammation, metabolic syndrome or measurable bacterial translocation across the mucosal barrier in tumor-bearing mice housed in our facilities, including TLR5-deficient animals. In fact, the signal of PCR amplification of $16 \mathrm{~S}$ ribosomal RNA at tumor, lymphatic or other non-mucosal locations was

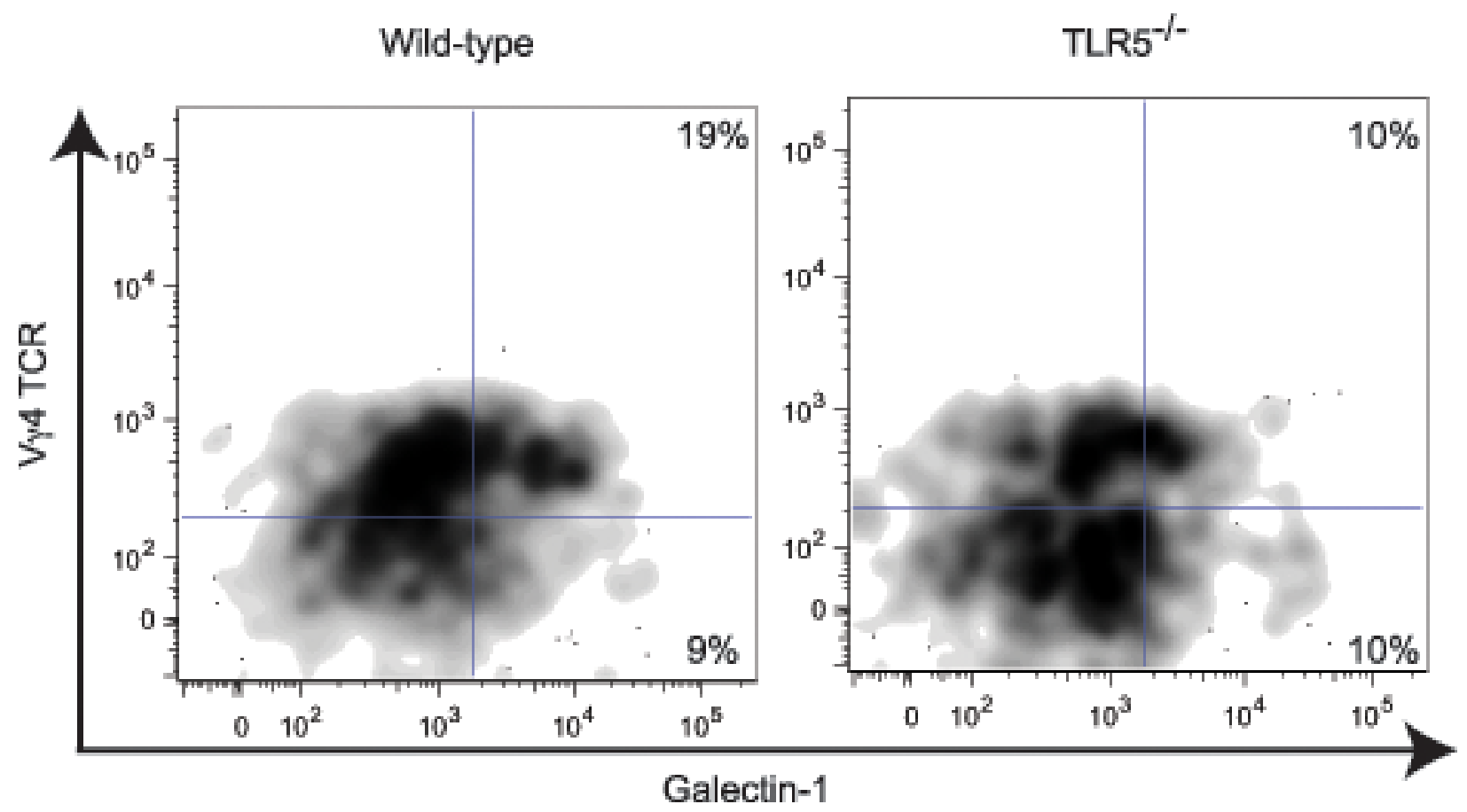

Figure 1: Galectin-1 producing $\gamma \delta \mathbf{T}$ cells are predominantly $\mathbf{V} \boldsymbol{\gamma} \mathbf{4} \mathbf{T C R}+$. Intracellular cytokine staining of $\gamma \delta \mathrm{T}$ cells from the tumor-draining lymph nodes of wild-type or TLR5 $5^{-/}$tumor-bearing mice. Plots are gated on Live, $\mathrm{CD}^{+} 5^{+}, \mathrm{CD}^{+}, \gamma \delta \mathrm{TCR}{ }^{+}$. Numbers represent the proportion of $\gamma \delta \mathrm{T}$ cells that are galectin $-1^{+}$and $\mathrm{V} \gamma 4 \mathrm{TCR} \mathrm{T}^{+}$.

never higher than the signal detected in wild-type tumorfree mice [25]. Although we cannot rule out that bacterial products still translocate and have a significant effect in the activation of distal immune cells, we were unable to detect measurable levels of endotoxin in serum or tumor ascites. In contrast, an obvious metabolic syndrome and the presence of colitis and significant increases in the levels of IL- $1 \beta$ within their colons was confirmed in the same TLR5 ${ }^{-/}$mouse housed in different facilities [33-35].

\section{GENETIC VARIATION IMPACTS THE RESPONSE TO COMMENSAL MICROORGANISMS}

Interactions between the microbiome and mucosal surfaces are regulated in part by stimulation of innate immune "pattern recognition receptors" (PRRs). PRRs are proteins that recognize pathogen-associated molecular patterns (PAMPs), associated with microorganisms or damage-associated molecular patterns (DAMPS), associated with cellular stress. In mammals, these molecules can be broadly classified into membrane-bound PRRs, which include Toll-like receptors (TLRs) and the mannose receptor; and cytoplasmic PRRs, which include NOD receptors, NALPs and RNA Helicases.

Interestingly, At least $30 \%$ of individuals in the general population are carriers of polymorphisms in PRR genes. For instance, up to $23 \%$ of individuals in the general population have detrimental mutations affecting cell-surface TLRs [36]. In addition, $16 \%$ of individuals 
carry nonsense mutations in at least one of these TLRs. The most frequent loss-of-function for any TLR is associated with the R392X variant of TLR5, which has a dominant-negative effect and affects $\sim 7-10 \%$ of the general population [37]. TLR5 is the pathogen recognition receptor (PRR) for flagellin, which is exclusively a bacterial product. Functional TLR10 polymorphisms are also very frequent, affecting up to $5 \%$ of the general population. Another very frequently altered PRR is NOD2/ CARD15. Polymorphisms in the 3 most common hotspots are as frequent as $7.8 \%$ in Caucasians [38], and confer a risk for the development of Crohn's disease.

Multiple polymorphisms of functional relevance are also found in other important viral sensors such as the RNA helicase RIG-I. The most significant effect in function occurs due to a SNP in codon $183(\mathrm{~S}>\mathrm{I})$, which induces an abortive conformation of RIG-I, rendering it incapable of downstream signaling [39]. However, the frequency of this polymorphism in the general population is unknown.

These frequent deficiencies in PRRs are obviously compatible with a healthy life, which indicates lack of evolutionary pressure and suggests a redundant biological role. However, some of these polymorphisms have immunological consequences, because they alter the susceptibility of the host to develop certain diseases. For instance, TLR5-deficient individuals are more susceptible to develop pneumonia caused by Legionella pneumophila [37], and are less likely to develop lupus. In contrast, $32 \%$ of patients with Chron's disease have common NOD2 polymorphisms, which is associated with more aggressive disease [40].

Our recent studies indicate that the dominant negative R392X TLR5 polymorphism determines the nature of tumor-promoting inflammation in the presence of a tumor at sterile (extra-mucosal) locations [25]. In tumor-bearing individuals, through interactions between the microbiome and $\mathrm{TLR} 5^{+}$cells that occur at places of bacterial colonization, TLR5 competence drives systemic IL-6 up-regulation, while deficiencies in TLR5 signaling are associated with higher circulating levels of IL-17. We know that flagellated bacteria and hematopoietic TLR5 ${ }^{+}$ cells at mucosal surfaces are driving differential tumor progression because: 1) depletion of commensal bacteria with a non-absorbable cocktail of antibiotics abrogates any TLR5-dependent differences in tumor growth; 2) and reconstitution of $\mathrm{TLR}^{+}$mice with TLR5-deficient (but not $\mathrm{TLR}^{+}$) bone marrow recapitulated the delayed progression of syngeneic and autochthonous tumors observed in TLR5 KOs. Paradoxically, we have shown that acute stimulation of TLR5 with flagellin boosts antitumor immunity in established ovarian cancer models [41].

Overall, our data illustrate the previously unrecognized importance of genetic variation in PRRs in the orchestration of tumor-promoting inflammation through interactions between the microbiome and the immune system, and open new avenues to understand dissimilar responses as a function of genetic factors.

\section{THE REPERTOIRE OF COMMENSAL BACTERIA DETERMINES INFLAMMATORY RESPONSES AND IS INFLUENCED BY GENETIC FACTORS}

Surprisingly, our studies have also identified that at least TLR5 deficiency drives significant and intrinsic differences in the composition of the microbiome [25]. Thus, these differences did not merely reflect divergence of the microbiota after long-term husbandry in isolation from each other, as previously reported [42]. Most shockingly, when TLR5-competent and TLR5-deficient mice were co-housed together for $>4$ weeks, variances in the composition of the microbiota remained, and differential malignant progression continued [25]. Because mice are coprohagic, co-housing should homogenize their microbiome if its composition is merely dependent on environmental conditions. However, our results illustrate that PRR-dependent changes in the host response are sufficient to alter the repertoire of at least commensal bacteria, independently of the effects of long-term cohousing of wild-type and mutant mouse strains [42]. Thus, we observed significant increases in the abundance of actinobacteria and firmicutes in TLR5-deficient mice, while bacteroidetes were expanded in TLR5-competent co-housed littermates [25]. Nevertheless, we found much more dramatic compositional differences in wild-type mice housed in a different vivarium, further illustrating how facility-dependent differences of animal husbandry may explain experimental differences in multiple studies as a result of dissimilar microbiomes, and urging caution in the interpretation of data that could be influenced by the microbiome.

The repertoire of mucosal microorganisms is important because certain strains favor particular inflammatory responses. For instance, seminal studies by the Littman laboratory demonstrated that segmented filamentous bacteria (SFB) drive the expansion of IL-17 producing cells [43]. Interestingly, we did not observe significance differences in SFB between TLR5-deficient and wild-type mice, despite the fact that they exhibit significantly higher serum levels of IL-17, at least in the presence of a tumor [25]. In contrast, other bacterial strains, including Bacteroides fragilis [4] and some Clostridia [44] promote the generation of regulatory $\mathrm{T}$ cells that dampen inflammation through the secretion of IL-10.

Because most bacteria colonizing with the intestines of healthy humans are included in one of four main phyla (Firmicutes, Bacteroidetes, Actinobacteria and Proteobacteria) [6], understanding the different contribution of each strain to the orchestration of systemic 
inflammatory responses and immune homeostasis could open new therapeutic avenues. Thus, adjusting the composition of the microbiome through antibiotics and oral enrichment of certain bacterial strains is a reality for the treatment of inflammatory diseases and could contribute to modulate inflammatory responses also in cancer patients. The feasibility of targeted microbiome reconstitution has recently been demonstrated to treat individuals that are susceptible for infection with Clostridium difficile [45].

Furthermore, while most studies have so far focused on the role of gut bacteria, much less is known about how commensal fungi or viruses influence biological processes, including malignant progression. Future studies should help to clarify the role of these additional components of the microbiome.

\section{DOUBLE-EDGE $\gamma \delta$ T CELLS INFLUENCE MALIGNANT PROGRESSION IN A MICROBIOTA-DEPENDENT MANNER}

Another unexpected novelty of our recent studies is a previously unrecognized contribution of $\gamma \delta$ T cells to the immunosuppressive burden in the microenvironment of different tumors, which is dependent upon the interactions of $\mathrm{TLR}^{+}$immune cells with the microbiota. $\gamma \delta \mathrm{T}$ cells are relatively abundant in solid ovarian or breast cancers of human origin, typically representing $>6 \%$ of total leukocytes and outnumbering Foxp $3^{+}$regulatory $\mathrm{T}$ cells [25].

Although the immunosuppressive activity of $\gamma \delta \mathrm{T}$ cells infiltrating breast cancer specimens was previously reported, those studies involved the use of selected clones [46]. In addition, the mechanisms of effector $\mathrm{T}$ cell suppression remained elusive. Our work demonstrates that bulk populations of $\gamma \delta \mathrm{T}$ cells in human and mouse tumors secrete more immunosuppressive galectin-1 on a per cell basis than any other cell type in the tumor microenvironment. Correspondingly, galectin-1 selectively secreted by tumor-derived $\gamma \delta \mathrm{T}$ cells was sufficient to promote accelerated tumor growth [25].

Galectin-1 is emerging as a major accomplice in malignant progression, through a variety of mechanisms that involve not only immunosuppression [47], but also angiogenesis [48] and the promotion of metastasis [49]. Relevant for its regulatory activity, secreted galectin-1 cross-links cell-surface glycoconjugates bearing multiple units of the N-acetyllactosamine (Gal $\beta 1-4-N A c G l c)$ disaccharide and abrogates potentially protective Th1 and CD8 effector T cell responses [50, 51]. Galectin-1 is highly abundant in ovarian cancer and there are multiple cellular sources, but our studies identify $\gamma \delta \mathrm{T}$ cells as major contributors to the immunosuppressive burden through the production of this crucial mediator.

$\gamma \delta$ T cells are significantly more abundant at mucosal locations and therefore the influence of the microbiota in their activities was not unexpected. However, perhaps one of the most intriguing aspects of our work is that the acquisition of regulatory attributes by $\gamma \delta$ T cells appears to take place at extra-mucosal locations and not locally at places of direct interactions with the microbiota. This is supported by the highest producers of galectin- 1 in the tumor microenvironment in $\gamma \delta \mathrm{T}$ cells carrying the $\mathrm{V} \gamma 4$ (Figure 1) and, to a lesser extent, the $\mathrm{V} \gamma 2$ (not shown) chains in mice, thus corresponding to subsets primarily located in the periphery rather than in the intestine. In addition, $\gamma \delta$ T cells sorted from the lymph nodes of healthy mice can be induced to secrete immunosuppressive galectin-1 in response to adenosine, which is generated at high levels by granulocytic (but not myelomonocytic) MDSCs [25]. Consequently, the suppressive activity of $\gamma \delta \mathrm{T}$ cells is entirely dependent upon TLR 5 signaling by commensal bacteria, so that $\gamma \delta$ T cells in TLR5-deficient tumor-bearing mice paradoxically show protective activity [25].

Future studies will help to establish the plasticity of $\gamma \delta$ T cells and the environmental cues required for the induction of immunostimulatory or immunosuppressive functions. Furthermore, it would be beneficial to define the full spectrum of functional activities of $\gamma \delta \mathrm{T}$ cells in ovarian cancer to enhance the potential of targeting or transforming them through novel interventions. For example, because our lab has recently demonstrated that FoxP1 is fundamental for TGF $\beta$ immune-mediated suppression in activated $\mathrm{T}$ cells [51], it would be interesting to determine whether targeting FoxP1 in ex vivo expanded $\gamma \mathrm{T}$ cells would enhance their anti-tumor effector functions.

\section{CONCLUSIONS AND FUTURE DIRECTIONS}

Humans are symbiotic organisms colonized by trillions of microbes. In recent years, it has become clear that the composition and abundance of the microbiome determines multiple physiological and pathological processes, including autoimmunity, responses to vaccination and infections, and cancer progression and therapy. A better understanding of the role of individual strains of bacteria during various inflammatory conditions could provide a means of mediating or abrogating systemic inflammation through the modulation of the composition (or the total burden) of commensal microorganisms. This will need to take into account the importance of genetic variation in interactions between the microbiome and mucosal surfaces, and in particular the role of frequent functional polymorphisms in PRRs. A better understanding of how the microbiota influences therapeutic responses $\boldsymbol{v s}$. spontaneous malignant progression in different types of cancer will also provide a rationale for antibiotic treatment 
and supplementation of more protective bacterial strains.

Many other open questions should be addressed in the next years. Among them, the role of commensal microorganisms different from bacteria (e.g., fungi or viruses) in inflammatory and adaptive immune responses, including those triggered by tumors. Furthermore, while it has been recently shown that the major human commensal bacterial phyla are resistant to the effects of inflammationinduced antimicrobial peptides [52], much more remains to be understood about whether other biological processes that alter the immune system (including cancer) influence the composition of the microbiota and, subsequently, other physiological and pathological events. Finally, why some inflammatory cytokines are produced in the presence of a tumor and are dependent upon the commensal microbiota needs to be further addressed.

Upcoming developments will clarify these and other issues and will provide a mechanistic rationale for the design of novel anti-cancer interventions.

\section{CONFLICT OF INTEREST}

The authors declare no competing financial interests.

\section{REFERENCES}

1. Mazmanian SK and Kasper DL. The love-hate relationship between bacterial polysaccharides and the host immune system. Nat Rev Immunol. 2006; 6(11):849-858.

2. Tlaskalova-Hogenova H, Stepankova R, Kozakova H, Hudcovic T, Vannucci L, Tuckova L, Rossmann P, Hrncir T, Kverka M, Zakostelska Z, Klimesova K, Pribylova J, Bartova J, Sanchez D, Fundova P, Borovska D, et al. The role of gut microbiota (commensal bacteria) and the mucosal barrier in the pathogenesis of inflammatory and autoimmune diseases and cancer: contribution of germ-free and gnotobiotic animal models of human diseases. Cell Mol Immunol. 2011; 8(2):110-120.

3. Gagliani N, Hu B, Huber S, Elinav E and Flavell RA. The fire within: microbes inflame tumors. Cell. 2014; 157(4):776-783.

4. Mazmanian SK, Round JL and Kasper DL. A microbial symbiosis factor prevents intestinal inflammatory disease. Nature. 2008; 453(7195):620-625.

5. Umesaki Y, Setoyama H, Matsumoto $\mathrm{S}$ and Okada Y. Expansion of alpha beta T-cell receptor-bearing intestinal intraepithelial lymphocytes after microbial colonization in germ-free mice and its independence from thymus. Immunology. 1993; 79(1):32-37.

6. Eckburg PB, Bik EM, Bernstein CN, Purdom E, Dethlefsen L, Sargent M, Gill SR, Nelson KE and Relman DA. Diversity of the human intestinal microbial flora. Science. 2005; 308(5728):1635-1638.

7. Macpherson AJ and Harris NL. Interactions between commensal intestinal bacteria and the immune system. Nat Rev Immunol. 2004; 4(6):478-485.

8. Huang T, Wei B, Velazquez P, Borneman J and Braun J. Commensal microbiota alter the abundance and TCR responsiveness of splenic naive CD4+ T lymphocytes. Clin Immunol. 2005; 117(3):221-230.

9. Ostman S, Rask C, Wold AE, Hultkrantz S and Telemo E. Impaired regulatory $\mathrm{T}$ cell function in germ-free mice. Eur J Immunol. 2006; 36(9):2336-2346.

10. Probert CS, Williams AM, Stepankova R, TlaskalovaHogenova H, Phillips A and Bland PW. The effect of weaning on the clonality of alpha beta T-cell receptor $\mathrm{T}$ cells in the intestine of GF and SPF mice. Dev Comp Immunol. 2007; 31(6):606-617.

11. Guy-Grand D, Cerf-Bensussan N, Malissen B, MalassisSeris M, Briottet C and Vassalli P. Two gut intraepithelial CD8+ lymphocyte populations with different $\mathrm{T}$ cell receptors: a role for the gut epithelium in $\mathrm{T}$ cell differentiation. J Exp Med. 1991; 173(2):471-481.

12. Shaw MH, Kamada N, Kim YG and Nunez G. Microbiotainduced IL-1beta, but not IL-6, is critical for the development of steady-state TH17 cells in the intestine. J Exp Med. 2012; 209(2):251-258.

13. Like AA, Rossini AA, Guberski DL, Appel MC and Williams RM. Spontaneous diabetes mellitus: reversal and prevention in the $\mathrm{BB} / \mathrm{W}$ rat with antiserum to rat lymphocytes. Science. 1979; 206(4425):1421-1423.

14. Kohashi O, Kuwata J, Umehara K, Uemura F, Takahashi T and Ozawa A. Susceptibility to adjuvant-induced arthritis among germfree, specific-pathogen-free, and conventional rats. Infect Immun. 1979; 26(3):791-794.

15. Feng $\mathrm{T}$, Wang $\mathrm{L}$, Schoeb TR, Elson CO and Cong Y. Microbiota innate stimulation is a prerequisite for $\mathrm{T}$ cell spontaneous proliferation and induction of experimental colitis. J Exp Med. 2010; 207(6):1321-1332.

16. Clarke TB, Davis KM, Lysenko ES, Zhou AY, Yu Y and Weiser JN. Recognition of peptidoglycan from the microbiota by Nod1 enhances systemic innate immunity. Nat Med. 2010; 16(2):228-231.

17. Abt MC, Osborne LC, Monticelli LA, Doering TA, Alenghat T, Sonnenberg GF, Paley MA, Antenus M, Williams KL, Erikson J, Wherry EJ and Artis D. Commensal bacteria calibrate the activation threshold of innate antiviral immunity. Immunity. 2012; 37(1):158-170.

18. Oh JZ, Ravindran R, Chassaing B, Carvalho FA, Maddur MS, Bower M, Hakimpour P, Gill KP, Nakaya HI, Yarovinsky F, Sartor RB, Gewirtz AT and Pulendran B. TLR5-mediated sensing of gut microbiota is necessary for antibody responses to seasonal influenza vaccination. Immunity. 2014; 41(3):478-492.

19. Wu S, Rhee KJ, Albesiano E, Rabizadeh S, Wu X, Yen HR, Huso DL, Brancati FL, Wick E, McAllister F, Housseau F, Pardoll DM and Sears CL. A human colonic commensal promotes colon tumorigenesis via activation of $\mathrm{T}$ helper 
type 17 T cell responses. Nat Med. 2009; 15(9):1016-1022.

20. Eisenring $M$, vom Berg J, Kristiansen G, Saller E and Becher B. IL-12 initiates tumor rejection via lymphoid tissue-inducer cells bearing the natural cytotoxicity receptor NKp46. Nat Immunol. 11(11):1030-1038.

21. Iida N, Dzutsev A, Stewart CA, Smith L, Bouladoux N, Weingarten RA, Molina DA, Salcedo R, Back T, Cramer S, Dai RM, Kiu H, Cardone M, Naik S, Patri AK, Wang E, et al. Commensal Bacteria Control Cancer Response to Therapy by Modulating the Tumor Microenvironment. Science. 2013; 342.

22. Viaud S, Saccheri F, Mignot Gg, Yamazaki T, Daill $\sqrt{\circledR r e}$ R, Hannani D, Enot D, Pfirschke C, Engblom C, Pittet M, Schlitzer A, Ginhoux F, Apetoh L, Chachaty E, Woerther P-L, Eberl Gr, et al. The intestinal microbiota modulates the anticancer immune effects of cyclophosphamide. Science (New York, NY). 2013; 342(6161):971-976.

23. Viaud S, Daillere R, Boneca IG, Lepage P, Pittet MJ, Ghiringhelli F, Trinchieri G, Goldszmid R and Zitvogel L. Harnessing the intestinal microbiome for optimal therapeutic immunomodulation. Cancer Res. 2014; 74(16):4217-4221.

24. Dzutsev A, Goldszmid RS, Viaud S, Zitvogel L and Trinchieri G. The role of the microbiota in inflammation, carcinogenesis, and cancer therapy. Eur J Immunol. 2015; 45(1):17-31.

25. Rutkowski MR, Stephen TL, Svoronos N, Allegrezza MJ, Tesone AJ, Perales-Puchalt A, Brencicova E, EscovarFadul X, Nguyen JM, Cadungog MG, Zhang R, Salatino M, Tchou J, Rabinovich GA and Conejo-Garcia JR. Microbially Driven TLR5-Dependent Signaling Governs Distal Malignant Progression through Tumor-Promoting Inflammation. Cancer cell. 2015; 27(1):27-40.

26. Pfirschke C, Garris C and Pittet MJ. Common TLR5 Mutations Control Cancer Progression. Cancer cell. 2015; 27(1):1-3.

27. Elinav E, Nowarski R, Thaiss C, Hu B, Jin C and Flavell R. Inflammation-induced cancer: crosstalk between tumours, immune cells and microorganisms. Nature reviews Cancer. 2013; 13(11):759-771.

28. Hu B, Elinav E, Huber S, Booth CJ, Strowig T, Jin C, Eisenbarth SC and Flavell RA. Inflammation-induced tumorigenesis in the colon is regulated by caspase- 1 and NLRC4. Proc Natl Acad Sci U S A. 2010; 107(50):2163521640.

29. Allen IC, TeKippe EM, Woodford RM, Uronis JM, Holl EK, Rogers AB, Herfarth HH, Jobin C and Ting JP. The NLRP3 inflammasome functions as a negative regulator of tumorigenesis during colitis-associated cancer. J Exp Med. 2010; 207(5):1045-1056.

30. Wolf KJ, Daft JG, Tanner SM, Hartmann R, Khafipour E and Lorenz RG. Consumption of acidic water alters the gut microbiome and decreases the risk of diabetes in NOD mice. J Histochem Cytochem. 2014; 62(4):237-250.
31. Sofi MH, Gudi R, Karumuthil-Melethil S, Perez N, Johnson BM and Vasu C. pH of drinking water influences the composition of gut microbiome and type 1 diabetes incidence. Diabetes. 2014; 63(2):632-644.

32. Letran SE, Lee SJ, Atif SM, Flores-Langarica A, Uematsu S, Akira S, Cunningham AF and McSorley SJ. TLR5deficient mice lack basal inflammatory and metabolic defects but exhibit impaired CD4 T cell responses to a flagellated pathogen. J Immunol. 2011; 186(9):5406-5412.

33. Vijay-Kumar M, Aitken JD, Carvalho FA, Cullender TC, Mwangi S, Srinivasan S, Sitaraman SV, Knight R, Ley RE and Gewirtz AT. Metabolic syndrome and altered gut microbiota in mice lacking Toll-like receptor 5. Science. 2010; 328(5975):228-231.

34. Vijay-Kumar M, Sanders C, Taylor R, Kumar A, Aitken J, Sitaraman S, Neish A, Uematsu S, Akira S, Williams I and Gewirtz A. Deletion of TLR5 results in spontaneous colitis in mice. The Journal of clinical investigation. 2007; 117(12):3909-3921.

35. Carvalho F, Nalbantoglu I, Ortega-Fernandez S, Aitken J, Su Y, Koren O, Walters W, Knight R, Ley R, VijayKumar M and Gewirtz A. Interleukin-1 $\beta$ (IL-1 $\beta$ ) promotes susceptibility of Toll-like receptor 5 (TLR5) deficient mice to colitis. Gut. 2012; 61(3):373-384.

36. Casanova JL, Abel L and Quintana-Murci L. Human TLRs and IL-1Rs in host defense: natural insights from evolutionary, epidemiological, and clinical genetics. Annu Rev Immunol. 29:447-491.

37. Hawn TR, Verbon A, Lettinga KD, Zhao LP, Li SS, Laws RJ, Skerrett SJ, Beutler B, Schroeder L, Nachman A, Ozinsky A, Smith KD and Aderem A. A common dominant TLR5 stop codon polymorphism abolishes flagellin signaling and is associated with susceptibility to legionnaires' disease. J Exp Med. 2003; 198(10):15631572 .

38. Hugot JP, Zaccaria I, Cavanaugh J, Yang H, Vermeire S, Lappalainen M, Schreiber S, Annese V, Jewell DP, Fowler EV, Brant SR, Silverberg MS, Cho J, Rioux JD, Satsangi $\mathrm{J}$ and Parkes M. Prevalence of CARD15/NOD2 mutations in Caucasian healthy people. Am J Gastroenterol. 2007; 102(6):1259-1267.

39. Pothlichet J, Burtey A, Kubarenko AV, Caignard G, Solhonne B, Tangy F, Ben-Ali M, Quintana-Murci L, Heinzmann A, Chiche JD, Vidalain PO, Weber AN, Chignard $\mathrm{M}$ and Si-Tahar M. Study of human RIG-I polymorphisms identifies two variants with an opposite impact on the antiviral immune response. PLoS One. 2009; 4(10):e7582.

40. Adler J, Rangwalla SC, Dwamena BA and Higgins PD. The prognostic power of the NOD2 genotype for complicated Crohn's disease: a meta-analysis. Am J Gastroenterol. 106(4):699-712.

41. Scarlett UK, Cubillos-Ruiz JR, Nesbeth YC, Martinez DG, Engle X, Gewirtz AT, Ahonen CL and Conejo-Garcia JR. In situ stimulation of CD40 and Toll-like receptor 3 
transforms ovarian cancer-infiltrating dendritic cells from immunosuppressive to immunostimulatory cells. Cancer Res. 2009; 69(18):7329-7337.

42. Ubeda C, Lipuma L, Gobourne A, Viale A, Leiner I, Equinda M, Khanin R and Pamer EG. Familial transmission rather than defective innate immunity shapes the distinct intestinal microbiota of TLR-deficient mice. J Exp Med. 2012; 209(8):1445-1456.

43. Ivanov, II, Atarashi K, Manel N, Brodie EL, Shima T, Karaoz U, Wei D, Goldfarb KC, Santee CA, Lynch SV, Tanoue T, Imaoka A, Itoh K, Takeda K, Umesaki Y, Honda $\mathrm{K}$, et al. Induction of intestinal Th17 cells by segmented filamentous bacteria. Cell. 2009; 139(3):485-498.

44. Atarashi K, Tanoue T, Oshima K, Suda W, Nagano Y, Nishikawa H, Fukuda S, Saito T, Narushima S, Hase K, Kim S, Fritz JV, Wilmes P, Ueha S, Matsushima K, Ohno $\mathrm{H}$, et al. Treg induction by a rationally selected mixture of Clostridia strains from the human microbiota. Nature. 2013; 500(7461):232-236.

45. Buffie CG, Bucci V, Stein RR, McKenney PT, Ling L, Gobourne A, No D, Liu H, Kinnebrew M, Viale A, Littmann E, van den Brink MR, Jenq RR, Taur Y, Sander C, Cross JR, et al. Precision microbiome reconstitution restores bile acid mediated resistance to Clostridium difficile. Nature. 2015; 517(7533):205-208.

46. Peng G, Wang HY, Peng W, Kiniwa Y, Seo KH and Wang RF. Tumor-infiltrating gammadelta $\mathrm{T}$ cells suppress $\mathrm{T}$ and dendritic cell function via mechanisms controlled by a unique toll-like receptor signaling pathway. Immunity. 2007; 27(2):334-348.

47. Rubinstein N, Alvarez $\mathrm{M}$, Zwirner $\mathrm{N}$, Toscano $\mathrm{M}$, Ilarregui J, Bravo A, Mordoh J, Fainboim L, Podhajcer
$\mathrm{O}$ and Rabinovich G. Targeted inhibition of galectin-1 gene expression in tumor cells results in heightened $\mathrm{T}$ cell-mediated rejection; A potential mechanism of tumorimmune privilege. Cancer cell. 2004; 5(3):241-251.

48. Croci DO, Cerliani JP, Dalotto-Moreno T, MendezHuergo SP, Mascanfroni ID, Dergan-Dylon S, Toscano MA, Caramelo JJ, Garcia-Vallejo JJ, Ouyang J, Mesri EA, Junttila MR, Bais C, Shipp MA, Salatino M and Rabinovich GA. Glycosylation-dependent lectin-receptor interactions preserve angiogenesis in anti-VEGF refractory tumors. Cell. 2014; 156(4):744-758.

49. Rabinovich GA. Galectin-1 as a potential cancer target. $\mathrm{Br}$ J Cancer. 2005; 92(7):1188-1192.

50. Toscano MA, Bianco GA, Ilarregui JM, Croci DO, Correale J, Hernandez JD, Zwirner NW, Poirier F, Riley EM, Baum LG and Rabinovich GA. Differential glycosylation of TH1, TH2 and TH-17 effector cells selectively regulates susceptibility to cell death. Nat Immunol. 2007; 8(8):825834.

51. Stephen TL, Rutkowski MR, Allegrezza MJ, PeralesPuchalt A, Tesone AJ, Svoronos N, Nguyen JM, Sarmin F, Borowsky ME, Tchou J and Conejo-Garcia JR. Transforming growth factor beta-mediated suppression of antitumor $\mathrm{T}$ cells requires FoxP1 transcription factor expression. Immunity. 2014; 41(3):427-439.

52. Cullen TW, Schofield WB, Barry NA, Putnam EE, Rundell EA, Trent MS, Degnan PH, Booth CJ, Yu H and Goodman AL. Gut microbiota. Antimicrobial peptide resistance mediates resilience of prominent gut commensals during inflammation. Science. 2015; 347(6218):170-175. 